\title{
The GOLD Rush
}

Joan B Soriano

The Gold Rush (figure 1), ${ }^{1}$ a 1925 classic silent movie by Chaplin, depicted him in his trademark little tramp character as a lone prospector searching for the precious metal somewhere in Alaska. On 16 November 2011, the release of the current revision of the Global Initiative for Chronic Obstructive Lung Disease (GOLD) Executive Summary in Shanghai, China, ${ }^{2}$ just recently published elsewhere, ${ }^{3}$ gave way to a new rush, the GOLD rush. Clinical guidelines need to be updated regularly to implement some of the vast knowledge about chronic obstructive pulmonary disease (COPD) accumulated over the last years, and to assess implementation and adherence. This second 5-year revision of the GOLD strategic document has somewhat shaken the COPD world for good.

The GOLD authors presented a new classification of COPD which intended to provide a better understanding of the impact of the disease on an individual patient than spirometry-only COPD staging, by collapsing four spirometry categories into just two, and adding exacerbations and symptoms. This is a threedimensional patient evaluation, as previously suggested by Lopez-Campos. ${ }^{4}$ A new classification with four groups (ABCD) was proposed, although GOLD might not have plucked stuff out of the air, and might have made an attempt to validate this $\mathrm{ABCD}$ system before it was included in their strategic document. So, investigators have raced to quantify the distribution of their own cohorts of patients according to these new COPD categories, also used to recommend treatment regimes with increasing dosage and/or number of drugs. But, the question is how to validate the new GOLD grading classification. Prognostic validity to predict mortality risk was something envisioned, being death both relevant at the individual and group levels.

Leivseth et $a l^{5}$ report an assessment of the old and new GOLD COPD classifications using a large cohort, the HUNT2 Nord-Trøndelag Health Study. This Norwegian cohort was originally aimed to study asthma, and now has also turned to other chronic conditions and disorders.

Correspondence to Dr Joan B Soriano, Program of Epidemiology and Clinical Research, Fundación CaubetCIMERA Illes Balears, Recinte Hospital Joan March, Carretera Soller Km 12, Bunyola 07110, Spain; jbsoriano@caubet-cimera.es
They studied 1540 COPD individuals from $1995-1997$ to 2012 , with a median follow-up of 14.6 years, totalling more than 18000 person-years, indeed a big study. The authors concluded that spirometric grades predicted mortality better than the newly proposed GOLD ABCD groups among people with COPD.

Before such strong conclusions are accepted, the advantages and demerits of their study need to be weighed in. The sheer size, extremely long follow-up and equipoised assessment of measurements in their study participants are definitive strengths. The gender analysis presented in all outcomes is commendable, and an example should be set. Their sensitivity analysis on the informativeness of respiratory symptoms and health status is novel. Last, but not least, is the uncanny ability of Scandinavian systems to trace individuals with no losses to follow-up up to death, due to the unique personal identifier of all inhabitants.

However, a big and long populationbased study also has limitations to be discussed beyond representativeness of clinical patients and borders. They used $1 \mathrm{mg}$ of terbutaline to obtain postbronchodilator values calculated from Norwegian reference equations. Starting with nearly a 100000 participants, HUNT2 ended up with 1540 spirometrically-defined COPD individuals, most of them with objectively milder COPD $(85 \%$ with a per cent predicted $\mathrm{FEV}_{1} \geq 50 \%$, or $61 \%$ grade $\mathrm{A}$ according to new GOLD). Also, they could determine the ABCD groups at baseline only in 1204 participants $(78.1 \%)$ as full information on symptoms and/or exacerbations was missing. The COPD Assessment Test (CAT) was not born at the time of study onset, and so symptoms were only assessed by a modification of their own questionnaire to resemble the modified Medical Research Council dyspnea score. Importantly, exacerbations in this COPD population were estimated by the reported use of oral steroids, a proxy of asthma, but highly debateable to represent all moderate to severe COPD exacerbations.

GOLD members insist their document is not a clinical guideline but a strategic document. Beyond semantics, sorting out by severity there should a consistency of risk, in this case mortality, from A to D. As expected, compared with the general population or those in COPD grade I, mortality increased with higher COPD grade (table 2 in Leivseth et $a l^{5}$ ). However, compared with group $\mathrm{A}$, only women in groups $\mathrm{C}$ and $\mathrm{D}$ and only men in group $\mathrm{D}$ had significantly increased mortality. Moreover, looking at the shape of their Kaplan-Meier curves, in HUNT2 in men these A to D groups start to diverge just after 5 years, while in women after 10 years, and this just to split $\mathrm{AB}$ from $\mathrm{CD}$.

So, the study by Leivseth et $a l^{5}$ is a welcome addition to the growing list of published replications just recently made available. $^{6-10}$ even including one in $\alpha_{1}$ antitrypsin deficiency. ${ }^{11}$ By reviewing these publications elsewhere, it appears B and $C$ groups have overlapping survival curves, $^{78}$ even reversed. ${ }^{6}$ Two of these studies actually conclude that GOLD 2011 did not differ significantly, both statistically and clinically, from GOLD 2007 in terms of mortality, ${ }^{7}$ respiratory hospitalisations and mortality. ${ }^{10}$ Are these ABCD categories worth their value to stratify COPD patients? Likely, there are more studies from different investigators and settings to come in the near future, and perhaps the initiative of sharing all data in a pooled meta-analysis at the patient-level would shed light on this GOLD rush.

The GOLD 2011 revision states that spirometry is required for making a clinical diagnosis of COPD. At the same time, the document has less emphasis on spirometric evaluation of disease severity and launches this combined assessment taking symptoms, spirometry and history of exacerbations into account. By grading COPD severity with the GOLD 2011 proposal, it is uncertain how many more patients are reclassified with a greater severity under the new classification, and thus graduate to more and more costly drugs, which should be assessed in future research. The GOLD document is updated annually and revised every 5 years. ${ }^{12}$ Clearly, the evidence is being built. Moving from assessing severity of airflow limitation only to assessing COPD severity by other domains is fundamental for seeing holistically any COPD patient. But, which and how many domains, their thresholds, and their construct validity need to be formally established.

It can be envisaged that different distributions of the ABCD grading categories will be seen in COPD patients from chest medicine versus internal medicine departments, primary care settings, the general population, in $\alpha_{1}$-antitrypsin deficiency also, or in those patients with COPD and comorbid conditions. Quoting Occam's razor, we miss the paucity and simplicity of the spirometry COPD severity. 


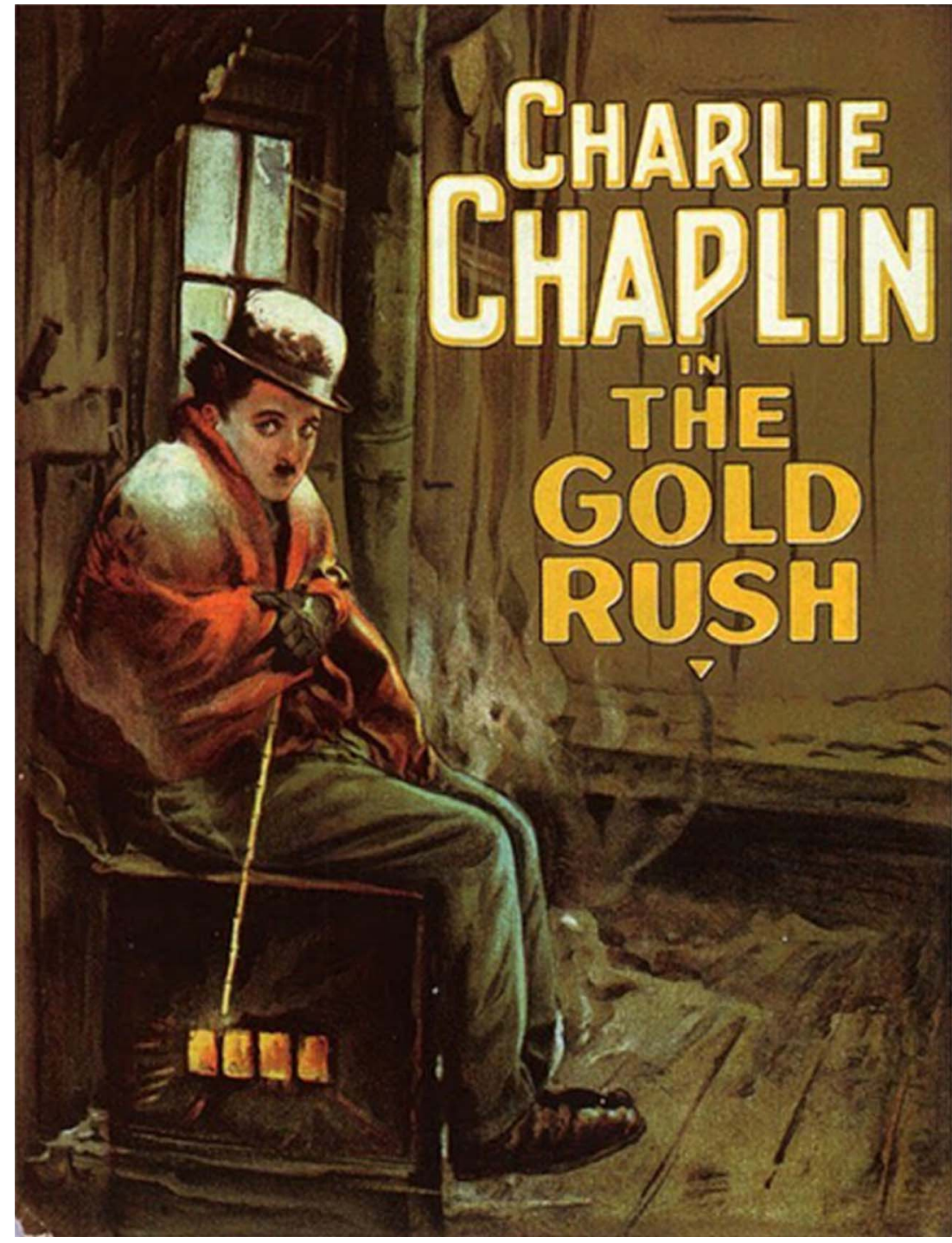

Figure 1 The Gold Rush. Original poster of the 1925 motion picture (as per http://www.google. com photo search on 10 April 2013).

Leivseth et $a l^{5}$ suggest keeping all four spirometric COPD grades in the combined COPD assessment in the next revision of the GOLD strategy document. Other options to stratify by severity, and even phenotype COPD patients, do exist. ${ }^{13}$ As already seen in the 11 cohorts pooled together in the Spanish COCOMICS study, even within a homogenous health system there might be great variability of GOLD stages, either in distribution or progression. ${ }^{7}$

To movie fans, Leivseth et al, ${ }^{5}$ and others to date, ${ }^{6-11}$ are like lone prospectors still chasing a gold mine together with Big Jim, to impress beloved Georgia, menaced by
Published Online First 12 June 2013

\section{Linked}

- http://dx.doi.org/10.1136/thoraxjnl-2013-203270

Thorax 2013;68:902-903.

doi:10.1136/thoraxinl-2013-203595

\section{REFERENCES}

1 The Gold Rush. Directed by Charlie Chaplin. Distributed by United Artists. Release date: 26 June 1925.

2 GOLD press release. Summary handout. of a GOLD conference sponsored by the Asian Pacific Society of Respirology in Shanghai, China, 6 November 2011. http://www.goldcopd.org/uploads/users/files/ GOLD2011_Summary.pdf (accessed April 10 2013).

3 Vestbo J, Hurd SS, Agustí AG, et al. Global strategy for the diagnosis, management, and prevention of chronic obstructive pulmonary disease: GOLD executive summary. Am J Respir Crit Care Med 2013;187:347-65.

4 Lopez-Campos JL. Treatment strategies in chronic obstructive pulmonary disease: a proposal for standardisation. Arch Bronconeumol 2010;46:617-20.

5 Leivseth L, Brumpton BM, Nilsen TIL, et al. GOLD classifications and mortality in COPD: The HUNT Study, Norway. Thorax 2013;68:914-21.

6 Lange P, Marott JL, Vestbo J, et al. Prediction of the clinical course of chronic obstructive pulmonary disease, using the new GOLD classification: a study of the general population. Am J Respir Crit Care Med 2012;186:975-81.

7 Soriano JB, Alfageme I, Almagro P, et al. Distribution and prognostic validity of the new GOLD grading classification. Chest 2013;143:694-702.

8 Han MK, Muellerova H, Curran-Everett, et al. GOLD 2011 disease severity classification in COPDGene: a prospective cohort study. Lancet Respir Med 2013;1:43-50.

9 Agusti A, Edwards L, Celli B, et al. Characteristics, stability and outcomes of the GOLD 2011 COPD groups in the ECLIPSE cohort. Eur Respir J Published Online First: 13 June 2013. doi: 10.1183/ 09031936.00195212.

10 Johannessen A, Nilsen RM, Storebø M, et al. Comparison of 2011 and 2007 GOLD Guidelines for Predicting Mortality and Hospitalization. Am J Respir Crit Care Med Published Online First: 5 April 2013. doi:10.1164/rccm.201212-22760C

Black Larsen and many other perils, in a journey through regions of ice, crossing Chilkoot Pass... There are indeed strengths and shortcomings of the GOLD 2011 severity proposal. ${ }^{14}$ Clearly COPD is a heterogeneous disease, and a mid-distance race, rather than a sprint, might be a model to quantify and determine the overall distribution, transitions within and prognostic validity of the next COPD grading system. ${ }^{3}$

\section{Competing interests None.}

Funding This research received no specific funding.

Provenance and peer review Commissioned; externally peer reviewed.

To cite Soriano JB. Thorax 2013;68:902-903. 